\title{
BETA STABILITY OVER BULL AND BEAR MARKET \\ ON THE WARSAW STOCK EXCHANGE
}

\author{
Prof. Wiesław Dębski \\ University of Finance and Management in Warsaw \\ Pawia 55 Str., 01-030 Warsaw, Poland \\ e-mail:wdebski@vizja.pl \\ Ewa Feder-Sempach, Ph.D. \\ University of Lodz, Faculty of Economics and Sociology \\ POW 3/5 Str., 90-255 Lodz, Poland \\ e-mail:ewafeder@wp.pl \\ Bartosz Świderski, Ph.D. \\ Warsaw University of Life Sciences \\ Nowoursynowska 159 Str., 02-776 Warsaw, Poland \\ e-mail: bartosz_swiderski@sggw.pl
}

Received 7 September 2015, Accepted 22 June 2016

\begin{abstract}
Beta parameter is one of the commonly used measures of the investment risk of individual stock or portfolio. It plays a crucial role in modern portfolio theory particularly in management of financial investment portfolios. In the field of beta parameter, numerous studies have been conducted,especially beta properties stability in the context of the stock market cycle phases, measuring frequency of rate of return, and the length of a sample period. There are much fewer studies concerned beta parameter in the countries of Central and Eastern Europe which have undergone systemic transformation at the end of the previous century. From a scientific point of view, it is interesting to know how the beta parameter behaves in these countries.

The main goal of this article is to examine the beta parameter stability over bull and bear market conditions on the Warsaw Stock Exchange. The paper presents an analysis of beta stability for 134 stocks of the largest companies listed at the WSE during years 2005-2013. To verify statistically the hypothesis of beta parameter stability, we used monthly returns in the Sharpe's single-index model. In the first part of the article, we present a brief review of the literature and methodology of the study, while in the second part, the obtained results and conclusions are shown.
\end{abstract}

Keywords: beta parameter, Sharpe's single-index model, bull and bear market, stability of beta, Warsaw Stock Exchange

JEL classification: G10 


\section{Introduction}

Beta parameter in the contemporary analysis of the portfolio is used intensively in a variety of theoretical considerations and empirical studies of the portfolio management of financial investments (strategies to invest in stocks, risk management), valuation of assets, and estimating the cost of capital. This parameter, introduced by Sharpe (1963) is a slope coefficient of the linear regression model conditioning the return of shares from the stock index rate of return, which represents market portfolio. It informs about the degree of sensitivity of the rate of return of the tested shares in relation to $1 \%$ change in the rate of return of the market portfolio, and is commonly used to measure the systematic risk of shares.

Particularly intensive research referring to beta parameter was carried out in highly developed economies, mainly in the United States where some features of beta parameter were tested, for example, its stability, mainly in the context of the exchange cycle phases (bull and bear market), and the prognostic strength. One of the first and more advanced works in this field was the publication of Blume (1971). His research indicated that the results obtained on the basis of historical data for individual stocks and smaller portfolios only in a small extent increase the forecasting accuracy. The accuracy was increasing significantly only with large portfolios. A similar conclusion was reached by Levy (1974). He examined beta parameter depending on the cycle phases of the stock exchange, dividing it into the upward and downward market, which resulted in a more accurate prediction of the systematic risk of the investment in shares. In turn, Fabozzi and Francis (1977), on the basis of their research, affirmed that there is no need to estimate separately beta parameters for upward and downward market. As estimated, beta parameters of the company shares are constant for both distinguished phases of the cycle of the stock exchange. The results of the analyzes of Kim and Zumwalt (1979) denied these conclusions. They found that beta parameters estimated separately for upward and downward market have greater prognostic strength.

The results of other authors in this field either confirmed the conclusion drawn from Levy's research or contradicted it. It is difficult to mention here the works of all the authors, but as an example the following works can be indicated: Eubank and Zumwalt (1979); Chen (1982); Alexander and Benson (1982); Fisher and Kamin (1985); Brennan and Copeland (1988); Lin and Chen (1990); Clarkson and Thompson (1990); Sercu et al. (2008); Berger (2013). In these works, beta parameter was also under consideration in the context of issues such as: length of the estimation sample, portfolio size, company size, liquidity of trading shares of the company on the stock exchange, frequency of measurement of the rate of return, etc. 
In addition to the research in the field of the stability of the beta parameter conducted on highly developed markets, there are also plenty of works published just after 2000, containing studies for developing economies, or those after the transition of the system. A relatively large number of such studies refers to the Indian economy. For example, Bhaduri and Durai (2006) found, on the basis of the monthly returns of 78 shares listed on the stock exchange in Mumbai from the period of 1999-2004, that the division of market to upward and downward does not affect the stability of the estimated beta parameters. In turn, Ray (2010) stated that the results of his research were inconclusive in most cases, however, for 9 out of 30 examined shares, the results clearly indicated the need to distinguish the phases of the stock exchange cycle with beta parameter estimation. Further studies of the Indian market concerning the stability of beta parameter during the periods of growth and decline in the stock market include the works of Singh (2008) and Deb Misra (2011).

The studies of beta parameter, including its stability, are also carried out in the economies after the transition of the political system. Worth mentioning here are the works of Polish researchers. The most extensive study was conducted by Feder-Sempach (2011), who carried out a broad analysis of investment risk on the Polish stock market, and estimated beta parameters for 20 largest companies for various intervals to assess the rate of return in the years of 2000-2008. Another important research was performed by Brzeszczynski et al. (2011). An empirical analysis of the intervaling effect of Polish shares was carried out on the beta parameter depending on the main market trend (Debski, Feder-Sempach, 2012). Additionally, the stability of the beta parameter was tested in the periods of downward and upward market on the Warsaw Stock Exchange (Debski et al., 2013). Considerations relating to beta parameter can also be found in the following works: Cwynar (2008); Witkowska (2008); Tarczyński (2009); and Kurach (2013).

Conducting studies on the beta parameter or, more broadly, the investment risk in developing economies, whose markets are generally called emerging markets, is scientifically justified, for instance, due to the comparison of the results of the studies conducted in developed economies with the results of research conducted in different emerging markets, which from the beginning of the twenty-first century have been published a lot. Poland belongs to the developing economies and, in the middle of the second decade of this century, its financial market is considered to be reasonably well-developed, and allows collecting a sufficiently long estimation sample. In addition, the prolonged financial crisis and, therefore, unstable financial market makes the study of certain features of beta parameter, such as its stability, more interesting from the scientific point of view. 
The primary goal of this article is to investigate the stability of beta parameter for the largest companies listed on the Warsaw Stock Exchange. There were over 850 companies with the total capitalization of over USD 300 billion, listed there at the beginning of 2014. It must also be highlighted that the Polish financial market has been built from the scratch since the outset of transformation of the political and government system (in 1989). Thus any serious empirical research on the Polish capital market is of significance mainly from the cognitive and practical perspective. From the scientific point of view, it is interesting to examine whether the beta parameter for the studied companies remains stable, especially if the market is divided into the bull and the bear market. Whereas from the empirical point of view, such research supplies investors (both institutional and individual) with information about the degree of systematic risk and maintaining its stability, which is important at making investment decisions. It is also worth studying the beta parameter for Polish companies, so that it becomes possible to compare the results with the outcome of the research performed on the developed or other developing markets. In this context, the results of our research can be useful on the international markets, due to the fact that the Polish capital market is becoming more and more significant in the world, as demonstrated by almost $50 \%$ of shares of foreign institutional investors in the turnover volume on the Warsaw Stock Exchange.

The study was conducted for monthly rates of return from the period 2005-2013, divided into periods of growth (bull market) and decline (bear market), whereby the classification was based on two definitions of these markets. This sample including both periods of boom and slump in the stock market is very well suited for the study of stability of beta parameter. The hypothesis, that the parameters of beta shares for 134 largest companies listed on the Warsaw Stock Exchange during the period considered are stable, will be verified. Beta parameters are estimated using the ordinary least squares method with the use of the single-index model of Sharpe's. Thiswas the first test of beta parameter stability made for such a large number of companies (134) in Poland, the length of the sample (108 monthly returns), and made for the bull and bear markets which practically enabled the crisis on the financial market of 2007-2009. These are the only studies made on such a large scale.

\section{Methodology of the conducted study}

For the study, shares of 134 largest companies listed on the Warsaw Stock Exchange (at the end of 2013 there were 450 listed companies) in the period of 2005-2013 have been selected. For them, monthly rates of return (108 observations for each company) were adopted, calculated 
on the basis of closing prices on the last trading day of the month (excluding dividend income) defined by the following formula:

$$
R_{i t}=\left(\ln P_{i t}-\ln P_{i, t-1}\right) \times 100
$$

where:

$R_{i t}$ - rate of return of the $i$-th share in the month $t$,

$P_{i t}$ - price of the $i$-th share in the month $t$.

Then, the tested period was divided, what is the most important problem in the current study, into sub-periods - the bull market and bear market. The division was made according to the following two definitions (DEF1 and DEF2) encountered in the literature of the subject:

1. DEF1 - the basic period of the Warsaw Stock Exchange Index (WIG) from the bottom (the lowest value of the index) to the peak (the highest value of the index) is a bull market, and the period from the peak to the bottom is a bear market. The chart of the WIG index is shown in Figure $1 .^{1}$

2. DEF2 - the period in which the rate of return of the WIG index is greater in the month $\mathrm{t}$ than the rate of return in the month $t-1$, is a period of bull market, and the period in which the rate of return of the WIG index in the month $t$ is less than the rate of return in the month $t-1$, is the period of the bear market.

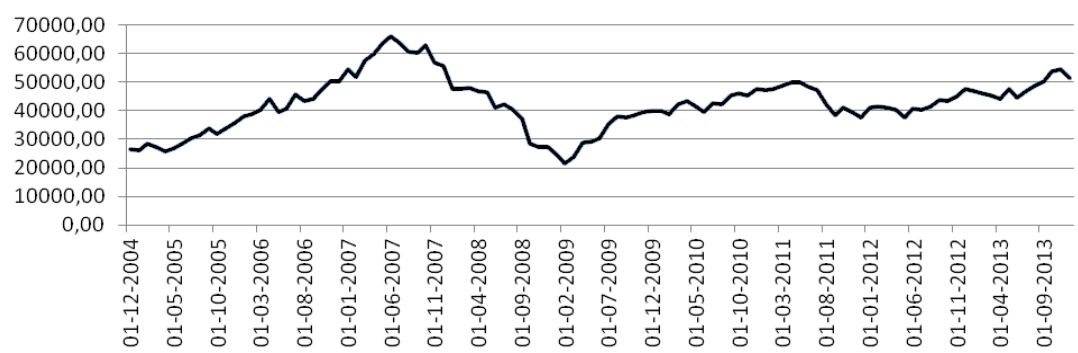

Figure 1. Chart of the WIG index in the years of 2005-2013

Source: Thomson Reuters.

According to DEF1, there are the following sub-periods and numbers of observations:

a) periods of bull market: 31.01.2005-30.11.2007,31.07.2009-31.07.2011, and 31.08. 2012-31.12.2013 for the total of 77 observations;

\footnotetext{
1 WIG is a basic income stock index covering all the Warsaw Stock Exchange listed companies.
} 
b) periods of bear market: 31.12.2007-30.06.2009 and 31.08.2011-31.07.2012 for the total of 31 observations, while according to DEF2 there are 61 observations for the bull market and 47 for the bear market.

To estimate beta parameters of the surveyed companies on the bull and bear market, Beta Dual Market Model - DBMM (Bhaduri, Durai, 2006) was used in the form of:

$$
R_{i t}=\alpha_{i}+\beta_{i H} D_{1} R_{W I G, t}+\beta_{i B} D_{2} R_{W I G, t}+\varepsilon_{i t}
$$

where:

$R_{W I G, t}$ - rate of return of the WIG index in the month $t$,

$D_{1}=1$ for the bull market and 0 for the bear market,

$D_{2}=0$ for the bull market and 1 for the bear market,

$\alpha_{i} \quad-$ intercept of the $i$-th stock,

$\beta_{i H} \quad$ - beta parameter for the bull market of the $i$-th share,

$\beta_{i B} \quad-$ beta parameter for the bear market of the $i$-th share,

$\varepsilon_{i t} \quad-$ random term of the $i$-th stock in the month $t$.

This model is derived from the single-index Sharpe's model, which has the form:

$$
R_{i t}=\alpha_{i}+\beta_{i} R_{W I G, t}+\varepsilon_{i t}
$$

where $\beta_{i}$ is the beta parameter measuring the impact of the rate of return of the stock exchange index on the rate of return of the $i$-th share, also interpreted as the ratio of the sensitivity of the rate of return of shares on the changes of the rate of return of the stock exchange index.

\section{Discussion of the obtained results}

\subsection{Study of the stochastic structure}

Before the actual start of the research, i.e. the research of the stability of beta parameters during the period of the bull market and bear market for the largest Polish listed companies, the study of stochastic structure had been conducted including primarily a test whether the adopted for calculations logarithmic rates of return of shares of the companies surveyed throughout the sample period follow a normal distribution. It is a key assumption used in many analyzes of the capital market, allowing to conclude further about the statistical accuracy of the obtained results of the estimated models. To verify the hypothesis about the normality of distribution of the rate of return, the statistics of the test of Jarque-Bera was used. Table 1 shows the results of this verification. 
Table 1 . The frequencies of rejections for the test of normality of distribution of the rate of return

\begin{tabular}{|c|c|c|}
\hline pval $<0.01$ & pval $<0.05$ & pval $<0.1$ \\
\hline 0.656716 & 0.798507 & 0.828358 \\
\hline
\end{tabular}

Source: own calculations.

It implies that at the level of significance of 0.05 , the rejection of the hypothesis of normality of the logarithmic rate of return occurs for about $80 \%$ of the surveyed companies, which means 107 companies of the surveyed population. Generally, relatively high fractions of rejections of the hypothesis are visible, which suggests a lack of normality of distribution of monthly logarithmic returns of the companies investigated.

Subject to further research was the beta parameter divided into periods of the bull market and bear market, highlighted according to the assumed definitions DEF1 and DEF2. These parameters for all 134 companies were estimated with the ordinary least squares method (OLS) based on model (2). First of all, the stability of beta parameters was examined in the two periods (in accordance with the main objective of the article), as well as the characteristics of the stochastic structure of the estimated model. Since presentation of the results relating to these two issues for all the companies would take a lot of space in the article, therefore, it was decided to aggregate the presentation of the obtained results. Thus Table 2, presents the summarized fractions (frequencies) of rejections of the examined hypotheses regarding the stability of beta parameters during the periods of bull and bear markets, according to the assumed definitions DEF1 and DEF2, and the stochastic structure of the tested model for three levels of significance.

Table 2. Fractions of rejections of the verified hypotheses for the surveyed shares of companies

\begin{tabular}{|l|c|c|c|c|c|c|}
\cline { 2 - 7 } \multicolumn{1}{c|}{} & \multicolumn{3}{c|}{ DEF1 } & \multicolumn{3}{c|}{ DEF2 } \\
\cline { 2 - 7 } \multicolumn{1}{c|}{} & pval $\leq 0.01$ & pval $\leq 0.05$ & pval $\leq 0.1$ & pval $\leq 0.01$ & pval $\leq 0.05$ & pval $\leq 0.1$ \\
\hline $\operatorname{pval}\left(\alpha_{i}\right)$ & 0.0075 & 0.0821 & 0.1343 & 0.0373 & 0.1119 & 0.1791 \\
\hline $\operatorname{pval}\left(\beta_{i H}\right)$ & 0.7985 & 0.9254 & 0.9478 & 0.6119 & 0.7910 & 0.8731 \\
\hline $\operatorname{pval}\left(\beta_{i B}\right)$ & 0.7761 & 0.8657 & 0.8731 & 0.5448 & 0.7239 & 0.7985 \\
\hline pks & 1.0000 & 1.0000 & 1.0000 & 1.0000 & 1.0000 & 1.0000 \\
\hline pval $(\mathrm{DW})$ & 0.0672 & 0.1269 & 0.1866 & 0.0597 & 0.1343 & 0.2388 \\
\hline pval & 0.4328 & 0.5746 & 0.6045 & 0.4552 & 0.5970 & 0.6119 \\
\hline JB & 0.6343 & 0.7612 & 0.7836 & 0.6343 & 0.7762 & 0.8209 \\
\hline
\end{tabular}

Source: own calculations. 
Explanatory notes:

$\operatorname{pval}\left(\alpha_{i}\right) \quad-$ estimated level of significance in the test of the t-student for parameter $\alpha_{i}$;

$\operatorname{pval}\left(\beta_{i H}\right)$ - estimated level of significance in the test of the t-student for parameter $\beta_{i H}$;

$\operatorname{pval}\left(\beta_{i B}\right)$ - estimated level of significance in the test of the t-student for parameter $\beta_{i B}$;

pks - the level of significance for Kolmogorov-Smirnov test, $\mathrm{H}_{0}$ : the distribution of the rests comes from the distribution of $\mathrm{N}(0,1)$;

pval(DW) - estimated level of significance in the test of Durbin-Watson;

pval - estimated level of significance in the test of Breusch-Pagan (the test of homoscedasticity);

Estimated level of significance in the test of Jarque-Bera $\mathrm{H}_{0}$ : the distribution of the rest comes from a normal distribution.

Table 2 shows that the estimate of the parameter $\alpha_{i}$ of estimated model for the vast number of companies is insignificant from the statistical point of view. For example, at 0.05 significance level and the first definition of distinctions of bull and bear periods (DEF1), only for $8.21 \%$ of the companies,therating of this parameter is significant. For DEF2 and the significance level of 0.1 , this result amounts to almost $18 \%$. In turn, the estimate of the parameter $\beta_{i H}$ and $\beta_{i B}$ in the vast number of companies, for both accepted definitions of the period of bull and bear market, is significant from a statistical point of view. For example, at a significance level of 0.05 and DEF1 for $92.5 \%$ of companies, the assessment of beta parameter in the period of the bull market is significant, and at a significance level of 0.1 , the number of companies for which the assessment is significant rises to almost $95 \%$. This relatively high level of significance ratings beta parameter estimated in division for bull and bear market reflects well on the model adopted for the estimation. In addition, for model (2), coefficients of determination $\left(\mathrm{R}^{2}\right)$ were calculated, the results of which are included in Table 3 and described in the following histogram.

Table 3. Obtained values of the coefficients of determination (for 134 companies)

\begin{tabular}{|c|c|}
\hline Scope of $\mathrm{R}^{2}$ & The fraction of companies (\%) \\
\hline$<0.2$ & 40.3 \\
\hline$[0.2-0.4)$ & 46.3 \\
\hline$[0.4-0.6)$ & 10.4 \\
\hline$\geq 0.6$ & 3.0 \\
\hline
\end{tabular}

Source: own calculations. 


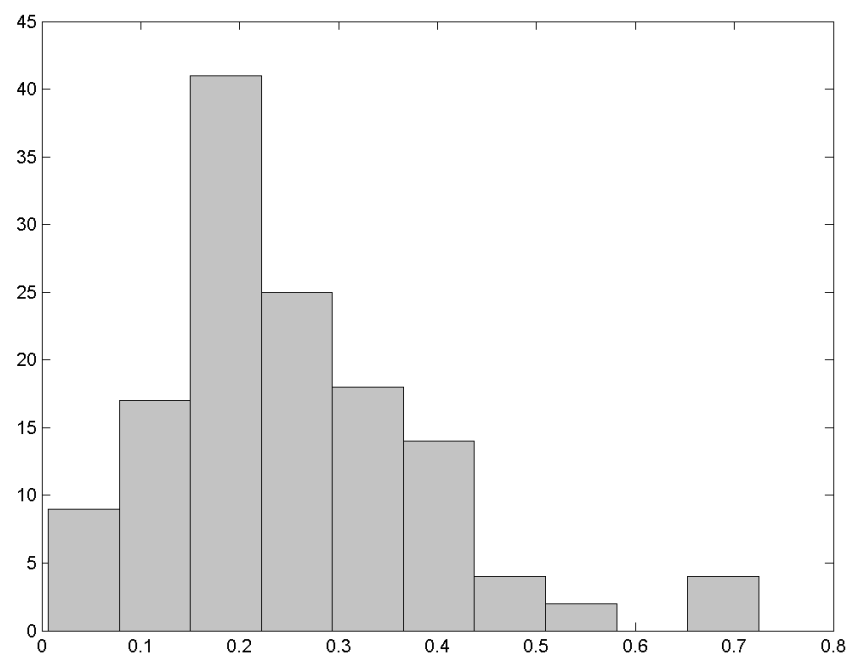

Figure 2. Obtained coefficients of determination

Source: own calculations.

In the histogram in Figure 2, on the $\mathrm{x}$-axis $(0 \mathrm{x})$, there are the coefficients ranges (bands), whereas on the ordinate axis $(0 y)$ - their quantities. The conducted calculations show that the coefficients of determination of the estimated rates of return for the surveyed companies amounted to relatively low levels - most of the values are in the range of $0.2-0.3$.

Within the research of hypotheses referring to the stochastic structure of the estimated model, in the first instance the hypothesis $\mathrm{H}_{0}$ was verified, stating that the distribution of rests of the estimated model (2) has a normal distribution with parameters 0 and 1 , which is $\mathrm{N}(0,1)$. This hypothesis was verified by the test of Kolmogorov-Smirnov. In Table 2, the rate of rejection for such a hypothesis, based on the test by Kolmogorov-Smirnov for three significance levels and both definitions of the period of the bull and bear market, contains the row marked by pks. It shows that for all the analyzed companies, the distribution of rests of the estimated model does not belong to the distribution $\mathrm{N}(0,1)$. The study of normality of rests of the model was also carried out with the test of Jarque-Bera. Stored in a row JB of Table 2, the frequency results for this test indicate that for the vast majority of the companies, the distribution of rests of the model does not belong to a normal distribution. For example, on the significance level of 0.05 in $76.1 \%$ of the analyzed companies (using DEF1), the rests of the estimated model do not have a normal distribution.

In the study of assumptions relating to the stochastic structure of the estimated model, the hypothesis of the existence of autocorrelation of the first order of random component and its 
homoscedasticity (equality of variance) was verified. In the first case, using the test of DurbinWatson $\mathrm{H}_{0}$, the lack of such autocorrelation was verified. As the results included in Table 2 in the row labeled pval(DW) show, in the vast majority of the companies in the estimated model, there is autocorrelation of the random component, since, for example, the hypothesis of the absence of such autocorrelation at 0.05 level should be rejected for $12.7 \%$ of the companies (according to DEF1), and $13.4 \%$ of companies (according to DEF2). In turn, the hypothesis of equality of variance of the random component of the estimated model was verified with the test of Breusch-Pagan (1979), dividing the time trial (108 observations) for each company into two equal halves, i.e. for $t=1,2, \ldots, 54$, and $t=55,56, \ldots, 108$. The results of the frequency for this test are included in the row marked pval in Table 2. They show that, for example, at a significance level of 0.05 for $57.5 \%$ of the companies using DEF1, and for $59.7 \%$ of the companies using DEF2, the hypothesis about the lack of homoscedasticity should be rejected.

In conclusion, the results relating to the test of the stochastic structure of the estimated model are as follows: for the majority of the investigated companies the basic assumptions underlying the use of the ordinary least squares method are not met, the received estimates of the parameters $\alpha_{i}, \beta_{i H}$, and $\beta_{i B}$ are not the Best Linear Unbiased Estimators (BLUE). This could give rise to certain problems, for example, in the case of using the estimated parameters to predict the rates of return on the shares of the analyzed or systematic risk assessment relating to the shares. This, however, is not the main purpose of the article.

\subsection{Examination of the stability of beta parameters}

The primary purpose of the article, as we pointed out, is to examine the stability of beta parameters in the period of the bull and bear market for the largest companies in the Warsaw Stock Exchange. The results of this study in the form of the rate of rejection of applied tests are summarized in Table 4.

Table 4. Fractions of rejections of verified hypotheses for surveyed shares of companies

\begin{tabular}{|l|c|c|c|c|c|c|}
\cline { 2 - 7 } \multicolumn{1}{c|}{} & \multicolumn{3}{c|}{ DEF1 } & \multicolumn{3}{c|}{ DEF2 } \\
\cline { 2 - 7 } \multicolumn{1}{c|}{} & pval $\leq 0.01$ & pval $\leq 0.05$ & pval $\leq 0.1$ & pval $\leq 0.01$ & pval $\leq 0.05$ & pval $\leq 0.1$ \\
\hline pChow & 0.0448 & 0.1343 & 0.1940 & 0.0299 & 0.1045 & 0.1567 \\
\hline p0 & 0.0075 & 0.0299 & 0.0672 & 0.0000 & 0.0373 & 0.0672 \\
\hline pval_$\beta_{i H}$ & 0.5075 & 0.6940 & 0.7687 & 0.2313 & 0.3881 & 0.5075 \\
\hline pval_$\beta_{i B}$ & 0.5299 & 0.6791 & 0.7388 & 0.2761 & 0.4478 & 0.5000 \\
\hline pval b1 & 0.1493 & 0.2910 & 0.4030 & 0.1418 & 0.2313 & 0.3582 \\
\hline pval b2 & 0.2239 & 0.3358 & 0.4030 & 0.1567 & 0.2313 & 0.3060 \\
\hline
\end{tabular}

Source: own calculations. 
Explanatory notes:

pChow - estimated level of significance in the Chow stability test $\left(\mathrm{H}_{0}\right.$ : beta during the bull market is equal to the beta in the period of bear market);

p0 - estimated level of significance in the test of Kolmogorov-Smirnov $\left(\mathrm{H}_{0}\right.$ : distributions of the rests in model (3) are the same for the period of the bull market and bear market);

pval_ $\beta_{i H}-$ estimated level of significance in the test, where $\mathrm{H}_{0}$ : estimation of $\beta_{i}$ parameter in the model (3) for the period of the bull market is equal to the value of the same ratio (treated as constant) for the period of the bear market;

pval_ $\beta_{i H}-$ estimated level of significance in the test, where $\mathrm{H}_{0}$ : estimation of $\beta_{i}$ parameter in the model (3) for the period of the bear market is equal to the value of the same ratio (treated as constant) for the period of the bull market;

pval b1 - estimated level of significance in the bootstrap 1 test;

pval b2 - estimated level of significance in the bootstrap 2 test.

The study of the stability was conducted with the four methods for beta parameters obtained from the estimation of the model (3) for the two definitions (DEF1 and DEF2) of the division of the entire sample period (monthly rate of return from 2005 to 2013 for 134 companies) for the periods of bull market and bear market.

1. In the first method, the stability of beta parameters was checked with the test of Chow. The null hypothesis $\left(\mathrm{H}_{0}\right)$ was verified, stating that beta parameters in the two distinguished periods are equal. The results in the form of a frequency of estimated values of the Chow test for three levels of significance are included in the line pChow in Table 4. They indicate (the lower value of the test, the easier it is to reject $\mathrm{H}_{0}$ ) that for the vast majority of the analyzed companies there is no reason to reject the hypothesis of equality of beta parameter in the period of the bull market and bear market. For example, for the level of significance of 0.05 , only $13.4 \%$ of the companies according to DEF1, and $10.4 \%$ of the companies according to DEF2, $\mathrm{H}_{0}$ should be rejected, and, respectively, in $86.6 \%$ and $89.6 \%$ there are no grounds for its rejection. This means that according to the Chow test, for the vast majority of the companies in the Warsaw Stock Exchange, beta parameters in the period of the bull and bear market, from a statistical point of view do not differ significantly from each other, which means that they are stable.

2. In the second method, the stability of beta parameters were examined with the test of Kolmogorov-Smirnov. The hypothesis $\mathrm{H}_{0}$ was introduced in such a way that it stated that the used for estimation parameters of the estimated model in the period of the bull and bear 
market, populations of rests (rates of return from the assumption differ in periods of the bull market (are positive) and bear market (are negative) for most observations) of the estimated rates of return have the same distribution. The results in Table 4, row p0, represent frequencies of the estimated values of the test by Kolmogorov-Smirnov relating to the verification of this hypothesis (the lower the value of the test the easier it is to reject $\mathrm{H}_{0}$ ). In our study, only for a small number of the analyzed companies, values of the p-value for this test are low. For the level of significance of 0.1 and both definitions of the period of bull market and bear market, values of rejection fraction for this test are not higher than $6.7 \%$ of the companies, which means that for such number of companies $\mathrm{H}_{0}$ should be rejected (for the level of significance of 0.05 , it is $3 \%$ and $3.7 \%$ respectively). This, therefore, supports the hypothesis of the lack of differences in the distributions of rests of equation (3) for periods of bull market and bear market (from the statistical point of view, there are no grounds to reject it). It also means that the examination with the test of Kolmogorov-Smirnov did not unequivocally deny the results of the research with the Chow test. The results obtained confirm the results of the study presented in Debski et al. (2013).

3. In another method of stability studies of beta parameters in the period of bull market and bear market, $\mathrm{H}_{0}$ was verified on equality of beta parameters in these periods, i.e. in the first case $\mathrm{H}_{0}$ was verified: $\beta_{i H}=\beta_{i B}$ ( $\beta_{i B}$ constants), and in the second case $\mathrm{H}_{0}: \beta_{i B}=\beta_{i H}$ ( $\beta_{i H}$ constants), wherein parameters were estimated on the basis of the model (3) respectively for a period of bull market and bear market. This means that these models were estimated for each company on a set of observations consisting of the distinguished periods of bull market and bear market according to the accepted definitions (DEF1 and DEF2). Verification of such a hypothesis takes place on the basis of t-student statistics Maddala (2008, p. 116). The frequencies of estimates of this statistic for three levels of significance are presented in rows pval $\beta_{i H}$ and pval $\beta_{i B}$ of Table 4. They show that, according to adopted in DEF1 period of bull market and bear market, in more than half (exactly $69.4 \%$ in the first case, and $67.9 \%$ in the second case, for the level of significance of 0.05 ) of the companies, there are no grounds to reject $\mathrm{H}_{0}$, which suggests the thesis that in most cases there are no grounds to reject the hypothesis of equality of these parameters (in the above sense). For the remaining number of companies, that is $30.6 \%$ and $32.1 \%$ respectively, at a significance level of 0.05 , these parameters are not stable. According to the second definition (DEF2) of periods of bull market and bear market, for a smaller number of the companies the beta parameters are stable (more precisely speaking, there is no reason to reject the hypothesis of their stability), respectively for $38.8 \%$ and $44.8 \%$. It also means that, 
according to this test and the definition of bull market and bear market period, for about $60 \%$ of the companies, beta parameters in these periods are not stable.

4. In the fourth method, the examination of stability of beta parameters in periods of bull market and bear market was based on a bootstrap procedure. Through 10,000 simulations, it was checked whether these parameters in the period of bull market and bear market have the same distributions. Two Bootstrap tests were used. Both are based on the equation (3) for a period of bull market and bear market. In the first approach (results in row b1 pval), separately for each time period, i.e. for bull market and bear market, observations are drawn in a bootstrap way, after which there is the beta parameter estimated in equation (3). After 10,000 simulations, we obtain a betas population for a period of bull market and bear market respectively, which we will callbetas_hossa and betas_bessa, as sets of 10,000 elements. We estimate also (without the bootstrap draws) the original parameters of equation (3) for periods of bull market and bear market, which are labeled as $\beta_{H}$ and $\beta_{B}$. Then, the following are estimated:

a) q_bessa - value corresponding to the row of quantile calculated in a set of betas_hossa which corresponds to (quantile of this row) the value of $\beta_{H}$;

b) q_hossa - value corresponding to the row of quantile calculated in a set of betas_bessa which corresponds to (quantile of this row) the value of $\beta_{B}$.

Calculating further pval1 = min (q_bessa, 1-q_bessa, q_hossa, 1-q_hossa), we obtain the probability of entry in the critical region for a one-sided test (in fact, we examine here the rejection of one of the two tests, in which we obtained bear market fall in the extreme quantile for the bull market, and vice versa). Moving to the two-sided area pval $2=2$ pval1, we obtain the probability of rejection of one of the tests. Since the aim is to determine the probability of rejection at least one of the tests, if we assume independence of the rejections of tests, we adjust the level of significance of cumulative probability of rejection of tests pval b1 $=2$ pval2 $-(\mathrm{pval} 2)^{2}$, yielding the estimation of the level of significance.

The second approach (results in row pval b2) is analogous, with one difference consisting of matching bootstrap observations. These observations are generated through the bootstrap addition of randomly selected rests (Bradley and Tibshirani, 1993) of equation (3) into a vector $\alpha+\beta R_{W I G}$, where $\alpha, \beta$ are estimates of regression coefficients (for the period of bull market and bear market respectively).

The frequencies for both tests contain rows pval b1 and pval b2 in Table 4 . These indicate that at the level of significance of 0.05 , according to DEF 1 , for about $30 \%$ of the companies the hypothesis of stability of the beta parameters in the period of bull market and bear market should be rejected, and according to DEF2 - for $23.1 \%$ of the companies. Adoption of the alternative 
hypothesis corresponds with the statement that for $70 \%$ or more of the analyzed companies, these parameters are stable.

In conclusion, the conducted four methods of stability studies gave basis to reach similar conclusions. First of all, they did not allow for an unambiguous statement that beta parameters in the period of bull market and bear market for 134 surveyed companies of the Warsaw Stock Exchange are stable or unstable. In general, it has been confirmed that for more than a half of the companies (with some of the tests, it is even more than $70 \%$ of the companies) these parameters are stable.

\subsection{The study of stochastic structure in the period of bull market and bear market}

In addition, it was decided to check the structure of the stochastic model for beta parameters in the period of bull market and bear market. This was done in such a way that single index model of Sharpe (3) was estimated separately for the period of bull market and bear market, i.e. the following models were estimated:

a) for the period of bull market:

$$
R_{i H t}=\alpha_{i H}+\beta_{i H} R_{W I G, t}+\varepsilon_{i H t}
$$

b) for the period of bear market:

$$
R_{i B t}=\alpha_{i B}+\beta_{i B} R_{W I G, t}+\varepsilon_{i B t}
$$

(marking the same as in model (2), the symbols $\mathrm{H}$ and B are the period of bull market and bear market respectively).

Models (4) and (5) were estimated with the ordinary least squares respectively for each company, for such number of observations that resulted from the number of observations associated with the distinguished periods of bull market and bear market in accordance with the definitions DEF1 and DEF2 of these periods. The results of studying the structure of stochastic models (4) and (5) are listed in Table 5.

The results presented in Table 5 clearly indicate that the estimates of parameter $\alpha_{i}$ in the estimated models are not significant from the statistical point of view. For the model of the bull market, and the level of significance of 0.05 , the number of significant estimates of this parameter does not exceed $9 \%$, and for the model of the bear market - $13 \%$, where the amount is less for the first definition (DEF1) of the bull market and bear market periods than the second one (DEF2). In contrast, the significance of the parameter $\beta$ (pval rows $\left(\beta_{i}\right)$ ) is much higher, since in the case of the model for the period of bull market and the level of significance 0.05 for 
Table 5. Fractions of rejections of the verified hypotheses for shares of the companies surveyed in the period of bull market and bear market

\begin{tabular}{|c|c|c|c|c|c|c|}
\hline & \multicolumn{6}{|c|}{ DEF1 } \\
\hline & \multicolumn{3}{|c|}{ bull market } & \multicolumn{3}{|c|}{ bear market } \\
\hline & pval $\leq 0.01$ & $\mathrm{pval} \leq 0.05$ & $\mathrm{pval} \leq 0.1$ & pval $\leq 0.01$ & pval $\leq 0.05$ & pval $\leq 0.1$ \\
\hline $\operatorname{pval}\left(\alpha_{i}\right)$ & 0.0000 & 0.0672 & 0.1194 & 0.0224 & 0.0522 & 0.1045 \\
\hline $\operatorname{pval}\left(\beta_{i}\right)$ & 0.7612 & 0.9254 & 0.9478 & 0.7388 & 0.8284 & 0.8881 \\
\hline pks & 1.0000 & 1.0000 & 1.0000 & 0.9925 & 1.0000 & 1.0000 \\
\hline pval(DW) & 0.0448 & 0.1045 & 0.1866 & 0.0299 & 0.0746 & 0.1045 \\
\hline \multirow[t]{4}{*}{ JB } & 0.5448 & 0.6418 & 0.7239 & 0.1567 & 0.2761 & 0.3657 \\
\hline & \multicolumn{6}{|c|}{ DEF2 } \\
\hline & \multicolumn{3}{|c|}{ bull market } & \multicolumn{3}{|c|}{ bear market } \\
\hline & pval $\leq 0.01$ & pval $\leq 0.05$ & pval $\leq 0.1$ & $\mathrm{pval} \leq 0.01$ & pval $\leq 0.05$ & pval $\leq 0.1$ \\
\hline $\operatorname{pval}\left(\alpha_{i}\right)$ & 0.0000 & 0.0896 & 0.1418 & 0.0373 & 0.1269 & 0.1866 \\
\hline $\operatorname{pval}\left(\beta_{i}\right)$ & 0.4627 & 0.6642 & 0.7239 & 0.4627 & 0.6119 & 0.6791 \\
\hline pks & 1.0000 & 1.0000 & 1.0000 & 1.0000 & 1.0000 & 1.0000 \\
\hline pval(DW) & 0.0522 & 0.1493 & 0.2015 & 0.0448 & 0.0896 & 0.1866 \\
\hline JB & 0.4776 & 0.6493 & 0.7239 & 0.3731 & 0.5522 & 0.6343 \\
\hline
\end{tabular}

Source: own calculations (marking the same as in Table 2).

$92.5 \%$ (according to DEF1) and $66.4 \%$ (according to DEF2) of the companies this parameter is important. For the model of the bear market, this parameter is important for a slightly smaller number of companies. The study results of the assumption of normality of the distribution of rests (rows pks) for the models (4) and (5) are the same as for the model (2) (see Table 2). Table 5 shows that the rests of both models for all the analyzed companies (based on the statistics of the test by Kolmogorov-Smirnov) do not belong to the distribution of $\mathrm{N}(0,1)$. This is confirmed by the results of the test of Jarque-Bera (JB rows). The resulting statistics indicate that on the basis of the estimated model for the period of the bull market and the level of significance of 0.05 , for slightly more than $64 \%$ of the companies the rests of model do not belong to a normal distribution. The estimated model for the bear market period indicates that for $27.6 \%$ (according to DEF1) and $55.2 \%$ (according to DEF2) of the companies, the rests do not have a normal distribution. The results of the research of the assumption on autocorrelation of the random component are included in the rows marked with pval (DW). They are also similar to those obtained for model (2) (see Table 2). They indicate that during the bull market at the significance level of 0.05 , for $10.4 \%$ (according to DEF1) or $14.9 \%$ (according to DEF2) of the companies, the hypothesis of absence of autocorrelation of the random component should be rejected. For the model of the bear market, it is respectively $7.5 \%$ and $9.0 \%$ of companies. This means that for the vast majority of the companies, there is autocorrelation of the random component of the first order. 


\section{Conclusions}

The study of stability of beta parameters in the period of the bull market and the bear market on the basis of monthly rates of return for 134 biggest companies of the Warsaw Stock Exchange, has brought interesting, from the scientific point of view, results. The four used methods of the research of the stability did not give a clear answer to the question whether these parameters are stable or not. In general, for more than a half of the investigated companies (i.e. for 60-70 percent, depending on the method used), beta parameters proved to be stable. This means that for 30-40 percent of the analyzed companies these parameters in the period of bull and bear market differ from the statistical point of view. It also means that there is a need for further research in this field, for example, carrying them out on a longer sample or divided into large, medium, and small companies. It was also noted that the degree of this stability depends on the definition of distinctions of the periods of bull market and bear market. It is also worth mentioning the relatively high statistical significance of the estimated beta parameters in the adopted models, but their drawback is the lack of fulfillment for most of the analyzed companies the assumption of normality of distribution of the logarithmic rate of return.

\section{References}

Alexander, G.J., Benson, P.G. (1982). More on Beta as a Random Coefficient. Journal of Financial and Quantitative Analysis, 17 (1), 27-36.

Berger, D. (2013). Financial Turbulence and Beta Estimation. Applied Financial Economics, 23 (3), 251-263.

Bhaduri, S., Durai, S. (2006). Asymetric beta in bull and bear market conditions: evidence from India. Applied Financial Economics Letters, 2, 55-59.

Blume, M.E. (1971). On the Assessment of Risk. Journal of Finance, 26 (1), 1-10.

Bradley, E., Tibshirani, R.J. (1993). An Introduction to the Bootstrap. New York: Chapman and Hall.

Brennan, M.J., Copeland, T.E. (1988). Beta Changes around Stock Splits: A Note. Journal of Finance, 43 (4), 1009-1013.

Breusch, T.S., Pagan, A.R. (1979). A Simple Test for Heteroskedasticity and Random Coefficient Variation. Econometrica, 47, 1287-1294. 
Brzeszczynski, J., Gajdka, J., Schabek, T. (2011). The Role of Stock Size and Trading Intensity in the Magnitude of the „Interval Effect” in Beta Estimation: Empirical Evidence from the Polish Capital Market. Emerging Markets Finance \& Trade, 47 (1), 28-49.

Chen, S. (1982). An Examination of Risk-Return Relationship in Bull and Bear Markets Using Time-Varying Betas. Journal of Financial and Quantitative Analysis, 17 (2), 265-286.

Clarkson, P.M., Thompson, R. (1990). Empirical Estimates of Beta When Investors Face Estimation Risk. Journal of Finance, 45 (2), 431-453.

Cwynar, W. (2008). Personalizacja w pomiarze ryzyka rynkowego (Personalization in the measurement of market risk). e-Finanse - Finansowy Kwartalnik Internetowy, 8, 1-10.

Deb, S.G., Misra, S. (2011). Are Equity Betas Stable? Evidence from Indian Equity Market. The IUP Journal of Applied Finance, 17 (4), 5-25.

Dębski, W., Feder-Sempach, E. (2012). Beta Coefficients of Polish Blue Chip Companies in the Period of 2005-2011. Folia OeconomicaStetinesia, 2, 90-102.

Dębski, W., Feder-Sempach, E., Świderski, B. (2013). Stabilność parametru beta w okresie rynku byka i niedźwiedzia dla największych spółek warszawskiej GPW. Journal of Management and Finance, 11 (2), 89-102.

Eubank, A.A., Zumwalt, J.K. (1979). An Analysis of the Forecast Error Impact of Alternative Beta Adjustment Techniques and Risk Classes. The Journal of Finance, 34 (3), 10151025 .

Fabozzi, F.F., Francis, J.C. (1977). Stability Tests for Alphas and Betas over Bull and Bear Market Conditions. The Journal of Finance, 32 (2), 1093-1099.

Feder-Sempach, E. (2011). Ryzyko inwestycyjne. Analiza polskiego rynku akcji. Warszawa: CeDeWu.pl Wydawnictwa Fachowe.

Fisher, L., Kamin, J.H. (1985). Forecasting Systematic Risk: Estimates of "Raw" Beta that Take Account of the Tendency of Beta to Change and the Heteroskedasticity of Residual Returns. Journal of Financial and Quantitative Analysis, 20 (2), 127-149.

Kim, M., Zumwalt, K. (1979). An Analysis of Risk in Bull and Bear Markets. Journal of Financial and Quantitative Analysis, 14 (5), 1015-1025.

Kurach, J. (2013). Does Beta Explain Global Equity Market Volatility - Some Empirical Evidence. Contemporary Economics, 7 (2), 55-66.

Lin, W.T., Chen, Y.H. (1990). Investment Horizon and Beta Coefficient. Journal of Business Research, 21 (1), 19-37.

Levy, R.A. (1974). Beta Coefficient as Predictors of Return. Financial Analysts Journal, 30 (1), 61-69.

Maddala, G.S. (2008). Ekonometria. Warszawa: Wydawnictwo Naukowe PWN.

Ray, K.K. (2010). Stability of Beta over Market Phases: An Empirical Study on Indian Stock Market. International Research Journal of Finance and Economics, 50, 174-189. 
Sercu, P., Vanderbroek, M., Vinaimont, T. (2008). Thin-Trading Effects in Beta: Bias v. Estimation Error. Journal of Business Finance and Accounting, 35 (9/10), 1196-1219.

Sharpe, W.F. (1963). A Simplified Model of Portfolio Analysis, Management Science, 9 (2), 277-293.

Singh, R. (2008). Beta Stationarity over Bull and Bear Markets In India. The Icfai Journal of Applied Finance, 14 (4), 32-47.

Tarczyński, W. (2009). O pewnym sposobie wyznaczania współczynnika beta na polskim rynku kapitałowym (About a method of determining the beta coefficient on the Polishcapital market). Zeszyty Naukowe Uniwersytetu Szczecińskiego, 561, 199-214.

Witkowska, D. (2008). Badanie stabilności współczynnika beta oszacowanego na podstawie prób o różnej długości (Examination of the stability of the beta parametr estimated from tests of differentlengths). Rynek Kapitałowy. Skuteczne inwestowanie. Studia i Prace Wydziatu Nauk Ekonomicznych i Zarządzania, 9, 143-154. 